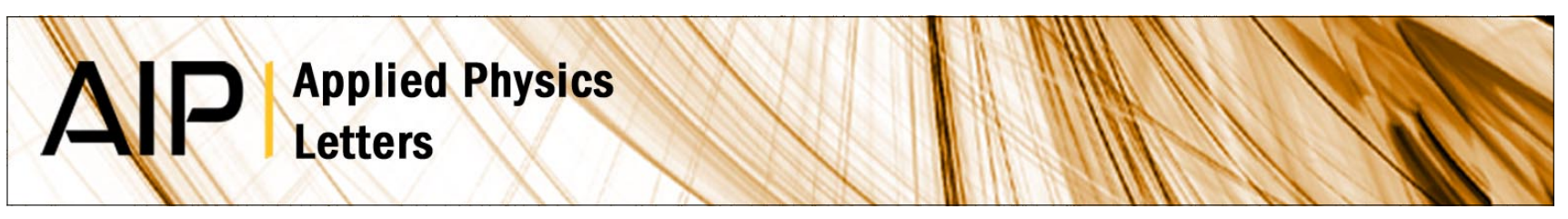

\title{
Fragility of iron-based glasses
}

Jong Hyun Na, Marios D. Demetriou, and William L. Johnson

Citation: Appl. Phys. Lett. 99, 161902 (2011); doi: 10.1063/1.3651763

View online: http://dx.doi.org/10.1063/1.3651763

View Table of Contents: http://apl.aip.org/resource/1/APPLAB/v99/i16

Published by the American Institute of Physics.

\section{Related Articles}

The electronic structure origin for ultrahigh glass-forming ability of the FeCoCrMoCBY alloy system J. Appl. Phys. 110, 033720 (2011)

Enhancement of glass-forming ability and corrosion resistance of Zr-based $\mathrm{Zr}$-Ni-Al bulk metallic glasses with minor addition of $\mathrm{Nb}$

J. Appl. Phys. 110, 023513 (2011)

Structural origin underlying poor glass forming ability of Al metallic glass

J. Appl. Phys. 110, 013519 (2011)

Interatomic potential to calculate the driving force, optimized composition, and atomic structure of the $\mathrm{Cu}-\mathrm{Hf}-\mathrm{Al}$ metallic glasses

Appl. Phys. Lett. 99, 011911 (2011)

Mechanical relaxation studies of and slow processes in Nd65Fe15Co10Al10 bulk metallic glass J. Appl. Phys. 109, 113524 (2011)

\section{Additional information on Appl. Phys. Lett.}

Journal Homepage: http://apl.aip.org/

Journal Information: http://apl.aip.org/about/about_the_journal

Top downloads: http://apl.aip.org/features/most_downloaded

Information for Authors: http://apl.aip.org/authors

\section{ADVERTISEMENT}

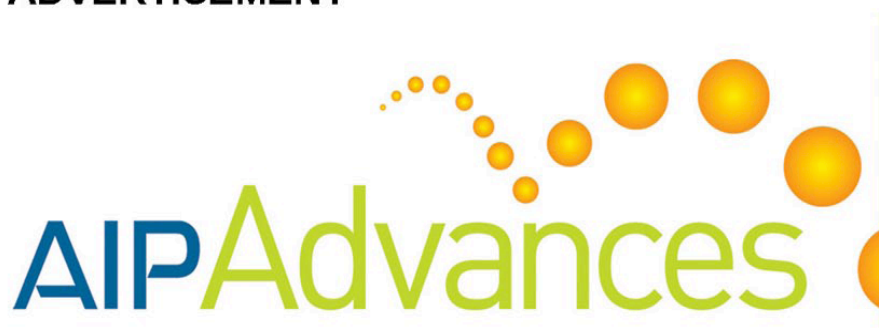

Submit Now

\section{Explore AIP's new \\ open-access journal}

Article-level metrics now available

Join the conversation! Rate \& comment on articles 


\title{
Fragility of iron-based glasses
}

\author{
Jong Hyun Na, Marios D. Demetriou, ${ }^{\text {a) }}$ and William L. Johnson \\ Keck Engineering Laboratories, California Institute of Technology, Pasadena, California 91125, USA
}

(Received 20 June 2011; accepted 12 September 2011; published online 17 October 2011)

\begin{abstract}
The viscosity of various iron-based bulk-glass-forming liquids is measured around the glass transition, and the associated fragility is calculated. Fragility is found to vary broadly between compositions, from a low value of $\sim 43$, which indicates fairly "strong" liquid behavior, to $\sim 65$, well within the region of "fragile" behavior. Despite a strong covalent bonding identified in the structure of this class of metal/metalloid glasses, their liquid fragility can be remarkably high, exceeding even the very fragile palladium and platinum bulk-glass formers. An inverse correlation between glass-forming ability and fragility is identified, suggesting that iron-based glasses are effectively "kinetically" stabilized. (C) 2011 American Institute of Physics. [doi:10.1063/1.3651763]
\end{abstract}

The fragility, $m$, of glass-forming liquids is a measure of the configurational breakdown in the liquid in the wake of the glass transition. The concept of fragility in supercooled glassforming liquids was originally proposed by Angell to facilitate the understanding of structural rigidity breakdown in the vicinity of the glass transition. ${ }^{1}$ Fragility is classically defined as the change in viscosity (in decades) with respect to in temperature around the glass transition. Glass-forming liquids can be largely classified according to their inherent bonding structure and how the bonding breaks down with increasing temperature, as "strong" liquid, "fragile" liquid, and an intermediate behavior. For "strongly bonded" glass-formers such as $\mathrm{SiO}_{2}, m$ is very small (20-40), and an Arrhenius behavior is closely followed. In glass-formers with "fragile" bonding structure, such as o-terphenyl (OTP), the breakdown deviates considerably from Arrhenius and is characterized by a higher $m$ (60-150). Most of bulk-metallic-glass formers are classified into the intermediate group (40-60). ${ }^{2}$

Bulk metallic glasses are newcomers in the class of glassy materials. Rheological studies on metallic glasses were focused mainly on early- and late-transition-metal glasses like $\mathrm{Zr}$ - and $\mathrm{Pd}$-based glasses, owing to their superior thermal stability and glass forming ability (GFA), ${ }^{3-5}$ but other families like rare-earth-metal glasses ${ }^{6}$ have also been thoroughly investigated. In recent years, efforts have been under way to develop bulk Fe-based "steel-type" amorphous alloys for structural applications. These efforts have been motivated largely by the remarkably high strength and stiffness associated with such glasses, ${ }^{7-11}$ attributed to a strong covalent metal/metalloid bonding induced by metalloids like $\mathrm{C}$ and B. ${ }^{12}$ Because of such covalent bonding, the liquid structure at the glass transition was anticipated to be relatively "strong," that is, the liquid fragility of Fe-based glasses was expected to be low. Fragility estimates for certain Fe-based glass-formers reported to date are based on approximations from calorimetric data rather than direct estimates from rheological data. ${ }^{13}$ In this study, by contrast, accurate rheological measurements and direct fragility estimates are performed for a broad range of Fe-based glass-for-

\footnotetext{
a) Author to whom correspondence should be addressed. Electronic mail: marios@caltech.edu. Tel.: 1-626-395-4425. Fax: 1-626-795-6132.
}

mers. A variety of alloy compositions was studied, including alloys bearing metalloids such as $\mathrm{C}, \mathrm{B}$, and $\mathrm{P}$, expected to display a varying degree of covalent bonding. We find that the fragility of the Fe-based glasses varies over an unusually large range between compositions, from a fairly strong behavior comparable to that of Zr-based glass-formers, to a rather fragile behavior, even more fragile than that of $\mathrm{Pd}-$ and Pt-based glass-formers. The very high fragility demonstrated by certain Fe-based glass-formers is unexpected and rather surprising, especially when considering the relatively high degree of covalent bonding identified in their structure. $^{13}$

Master alloys with the nominal compositions shown in Table I were prepared using raw materials with purity ranging from $99.9 \%$ to $99.9999 \%$ by means or two different techniques: induction melting in quartz tubes under high-purity argon (Alloy 2 and Alloy 3) and arc-melting over watercooled copper hearth in high-purity argon (Alloy 1, Alloy 4, and Alloy 5). Glassy rods 2-mm in diameter were obtained by two different techniques: (1) furnace melting in quartz tubes under high-purity argon and subsequent water quenching (Alloy 2 and Alloy 3) and (2) arc-melting over watercooled copper hearth in high-purity argon and subsequently suction-casting in copper mold (Alloy 1, Alloy 4 and Alloy 5). The glassy structure of the rods was confirmed using $\mathrm{X}$-ray diffractometry (XRD) and differential scanning calorimetry (DSC). Cylindrical glassy specimens for viscosity measurements were prepared by saw-cutting the rods into $12 \mathrm{~mm}$ long samples.

The equilibrium (Newtonian) viscosity in the supercooled liquid region was measured by three point beam bending using a thermo-mechanical analyzer (Perkin-Elmer TMA 7). The isothermal viscosity at a given temperature is determined by the following equation ${ }^{14}$ :

$$
\eta=-\frac{g L^{3}}{144 I_{c} v}\left(M+\frac{5 \rho A L}{8}\right),
$$

where $\eta$ is the apparent viscosity $(\mathrm{Pa} \cdot \mathrm{s}), g$ the gravitational constant $\left(\mathrm{m} / \mathrm{s}^{2}\right), L$ the support span length $(\mathrm{m}), I_{c}$ the cross sectional moment of inertia $\left(\mathrm{m}^{4}\right), v$ the midpoint deflection velocity $(\mathrm{m} / \mathrm{s}), M$ the applied load $(\mathrm{kg}), \rho$ the density $\left(\mathrm{kg} / \mathrm{m}^{3}\right)$, 
TABLE I. Glass transition temperature $T_{g}$ defined by a viscosity value of $10^{12} \mathrm{~Pa} \cdot \mathrm{s}$, critical rod diameter $d_{c}$, high-temperature limit of viscosity $\eta_{\infty}$, fit parameter $n$, and fragility parameter $m$ for various Fe-based bulk-glass-forming liquids.

\begin{tabular}{|c|c|c|c|c|c|c|c|}
\hline & Composition & $T_{g}(\mathrm{~K})$ & $d_{c}(\mathrm{~mm})$ & $\eta_{\infty}(\mathrm{Pa}-\mathrm{s})$ & Fit parameter $n$ & Fragility $m$ & Ref. \\
\hline Alloy 1 & $\mathrm{Fe}_{58} \mathrm{Co}_{6.5} \mathrm{Mo}_{14} \mathrm{C}_{15} \mathrm{~B}_{6} \mathrm{Er}_{0.5}$ & 756 & 4 & $6.1 \times 10^{-5}$ & 1.498 & 65 & 15 \\
\hline Alloy 2 & $\mathrm{Fe}_{74.5} \mathrm{Mo}_{5.5} \mathrm{P}_{12.5} \mathrm{C}_{5} \mathrm{~B}_{2.5}$ & 695 & 3 & $5.7 \times 10^{-5}$ & 1.437 & 63 & 17 \\
\hline Alloy 3 & $\mathrm{Fe}_{68} \mathrm{Mo}_{5} \mathrm{Ni}_{5} \mathrm{Cr}_{2} \mathrm{P}_{12.5} \mathrm{C}_{5} \mathrm{~B}_{2.5}$ & 688 & 6 & $5.8 \times 10^{-5}$ & 1.409 & 62 & 17 \\
\hline Alloy 4 & $\mathrm{Fe}_{48} \mathrm{Cr}_{15} \mathrm{Mo}_{14} \mathrm{C}_{15} \mathrm{~B}_{6} \mathrm{Y}_{2}$ & 822 & 9 & $5.9 \times 10^{-5}$ & 1.072 & 51 & 14 \\
\hline Alloy 5 & $\mathrm{Fe}_{41} \mathrm{Co}_{7} \mathrm{Cr}_{15} \mathrm{Mo}_{14} \mathrm{C}_{15} \mathrm{~B}_{6} \mathrm{Y}_{2}$ & 820 & 16 & $5.9 \times 10^{-5}$ & 0.812 & 43 & 16 \\
\hline
\end{tabular}

and $A$ is the cross sectional area $\left(\mathrm{m}^{2}\right)$. Loads ranging from 20 to $1600 \mathrm{mN}$ were applied.

The viscosity of $\mathrm{Fe}_{58} \mathrm{Co}_{6.5} \mathrm{Mo}_{14} \mathrm{C}_{15} \mathrm{~B}_{6} \mathrm{Er}_{0.5}$ (Alloy 1) measured isothermally at temperatures 743,753 , and $763 \mathrm{~K}$ is presented in Fig. 1. The viscosity is shown to increase sharply during relaxation of the glass from an initial "frozenin" value towards a unique value in the equilibrium liquid over a characteristic time. The temperature dependence of equilibrium viscosity for various Fe-based glasses is presented in Fig. 2. To describe the temperature dependence of viscosity, the cooperative shear model is employed ${ }^{15-17}$

$$
\frac{\eta_{e}(T)}{\eta_{\infty}}=\exp \left\{\frac{W_{g}}{k T} \exp \left[2 n\left(1-\frac{T}{T_{g}}\right)\right]\right\}
$$

where $\eta_{e}(T)$ is the equilibrium viscosity, $\eta_{\infty}$ the hightemperature limit of viscosity, which is approximated here by the Planck's limit defined as $\eta_{\infty} \approx h_{p} / v_{m}$ (where $h_{p}$ is the Planck's constant and $v_{m}$ the molar volume), $W_{g}$ is the activation energy barrier at the glass transition, approximated by $W_{g} \approx k T_{g} \log \left(\eta_{g} / \eta_{\infty}\right) \quad\left(\right.$ where $\left.\eta_{g} \equiv 1 \times 10^{12} \mathrm{~Pa} \cdot \mathrm{s}\right), n$ is the effective fragility parameter, $k$ the Boltzmann constant, $T$ the temperature, and $T_{g}$ the glass transition temperature associated with a viscosity value of $10^{12} \mathrm{~Pa} \cdot \mathrm{s}$. The fragility parameter $m$ can be related to $n$ via

$$
m=(1+2 n) \log \left(\frac{\eta_{g}}{\eta_{\infty}}\right) .
$$

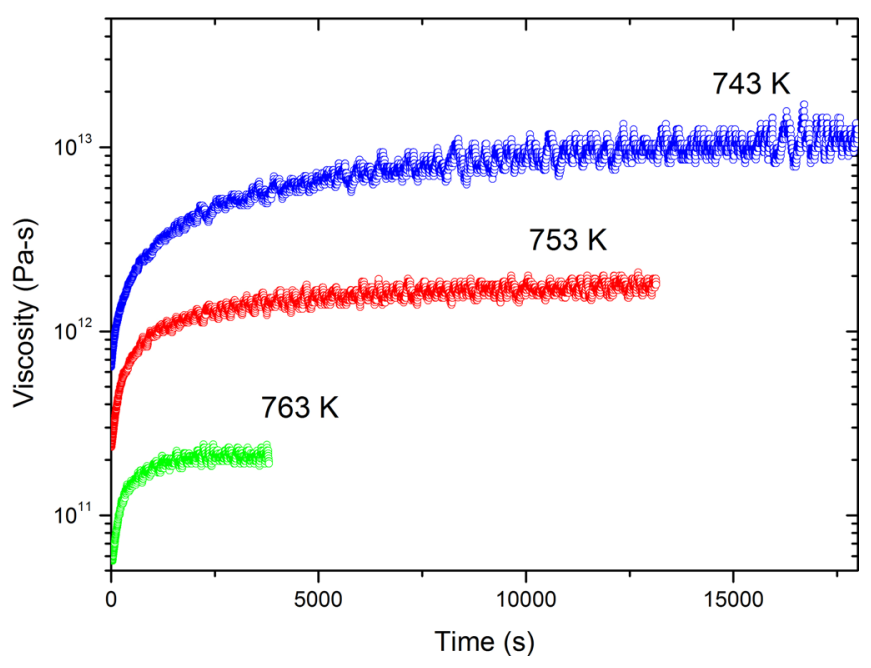

FIG. 1. (Color online) Transient isothermal viscosity relaxation of Alloy 1 $\left(\mathrm{Fe}_{58} \mathrm{Co}_{6.5} \mathrm{Mo}_{14} \mathrm{C}_{15} \mathrm{~B}_{6} \mathrm{Er}_{0.5}\right)$ measured at three different temperatures: 743, 753 , and $763 \mathrm{~K}$.
The fitting curves according to Eq. (2) for the various Febased glasses are superimposed on the data in Fig. 2, while the fit parameter $n$ and the calculated fragility $m$ are given in Table I. The fragility of the present glasses ranges from a value of 43 , which designates a fairly strong behavior, to a value of 65 , which is well within the region of fragile behavior. One may observe a trend by which high fragilities are associated with compositions having high ferrous-metal content (total atomic fraction of $\mathrm{Fe}, \mathrm{Ni}$, and $\mathrm{Co}>60 \%$ ), while lower fragilities are associated with compositions with low ferrous-metal content (total atomic fraction of $\mathrm{Fe}, \mathrm{Ni}$, and $\mathrm{Co}$ $<50 \%)$. Nevertheless, to identify the fundamental origin of fragility in these glasses, one would need to accurately assess the nature of chemical bonding (i.e., the degree of covalency) and range of topological order in the supercooled liquid state; this would be a challenging topic for future investigations.

In Fig. 3, a fragility (Angell) plot of various bulk-glassforming metallic liquids with fragilities ranging from 37 to 65 is presented. On this plot, the logarithm of the equilibrium viscosity data for each liquid is plotted against $T_{g} / T$. These liquids include $\mathrm{La}-\mathrm{Mg}$-, and $\mathrm{Zr}$-based glass-formers whose fragilities lie well within the "strong" fragility range (20-40), Pd- and Pt-based whose fragilities are close to the upper end of the intermediate fragility range (55-60), and a very fragile Fe-based liquid with $m=65$ (Alloy 1). As seen in the plot, the Fe-based glass-former undergoes the largest viscosity drop with increasing temperature, reflecting its very "fragile" character. The fragility of this Fe-based glassformer is unusually high, surpassing even that of the Ptbased glass former, which was thought to be the most fragile among the bulk metallic glass-formers. ${ }^{18}$

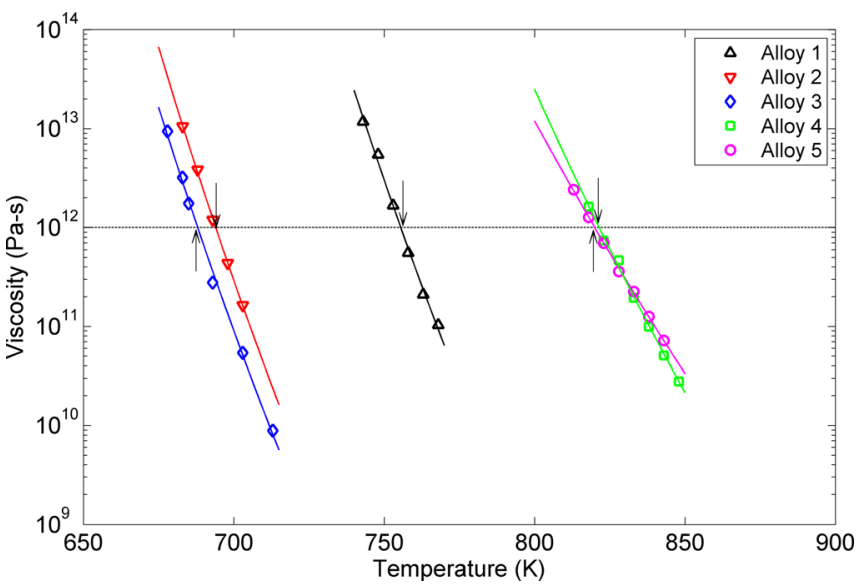

FIG. 2. (Color online) Equilibrium viscosity data for various Fe-based bulkglass-forming liquids. Lines are fits to the data using Eq. (2). Arrows designate glass-transition temperatures, based on a viscosity value of $10^{12} \mathrm{~Pa} \cdot \mathrm{s}$. 


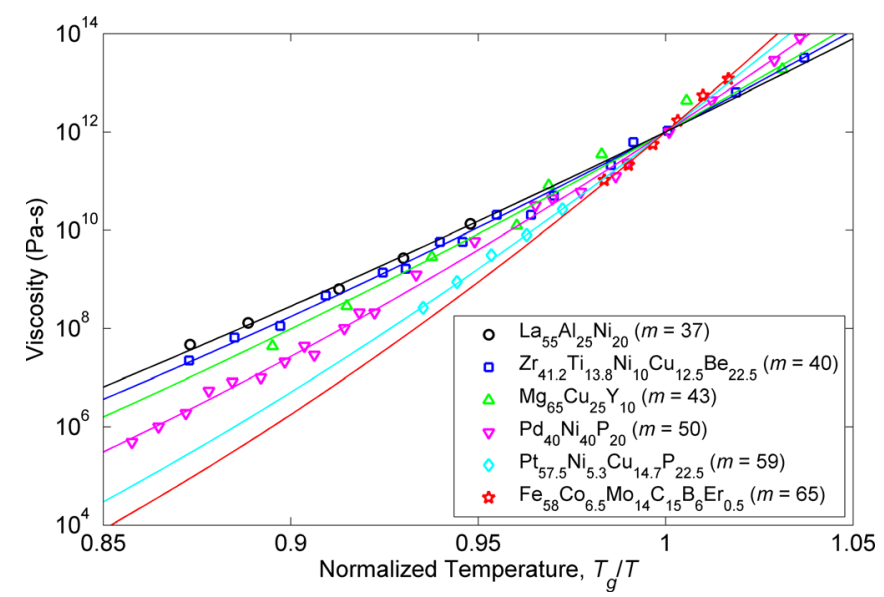

FIG. 3. (Color online) Angell fragility plots for various metallic bulk-glassforming liquids. Experimental viscosity data and associated fits for liquids other than the Fe-based are taken from Ref. 17.

Interestingly, the large fragility range of Fe-based glassformers appears to roughly reflect the broadly-varying GFA of these systems. Specifically, the Fe-based glasses whose fragilities, $m$, are estimated here to range from 43 to 65 have critical rod diameters for glass formation, $d_{c}$, ranging from 3 to $16 \mathrm{~mm}$. Fragile Fe-based glasses are associated with small $d_{c}$, while strong ones with large $d_{c}$. Hence, an inverse correlation between $d_{c}$ and $m$, or equivalently, a direct correlation between critical cooling rate $R_{c}$ and $m$, can be expected. In Fig. 4, the critical cooling rate $R_{c}$, estimated as $R_{c} \approx 1000 /$ $d_{c}^{2}(\mathrm{~K} / \mathrm{s})$, is plotted against $m$. A fairly tight correlation is revealed, reflecting a trend of increasing GFA with decreasing fragility. It is important to note here that his trend is not universal in all classes of bulk metallic glasses. Typically, metallic bulk-glass-forming systems can be classified into "thermodynamically stabilized" and "kinetically stabilized." "Thermodynamically stabilized" glasses are those whose formation is primarily attributed to thermodynamic suppression of the stable crystalline phase and is accommodated by a small driving force for crystallization. Such systems typically demonstrate GFA that increases as the equilibrium melting point decreases. "Kinetically stabilized" metallic glasses, on the other hand, are those whose formation is primarily attributed to kinetic suppression of the crystal phase, accommodated primarily by the buildup of liquid rigidity with decreasing temperature such that crystallization is effectively retarded. Such systems demonstrate GFA that increases with decreasing fragility. Owing to a fairly tight correlation between GFA and $m$, as presented in Fig. 4, one may conclude that Fe-based bulk-glass-formers are effectively "kinetically stabilized."

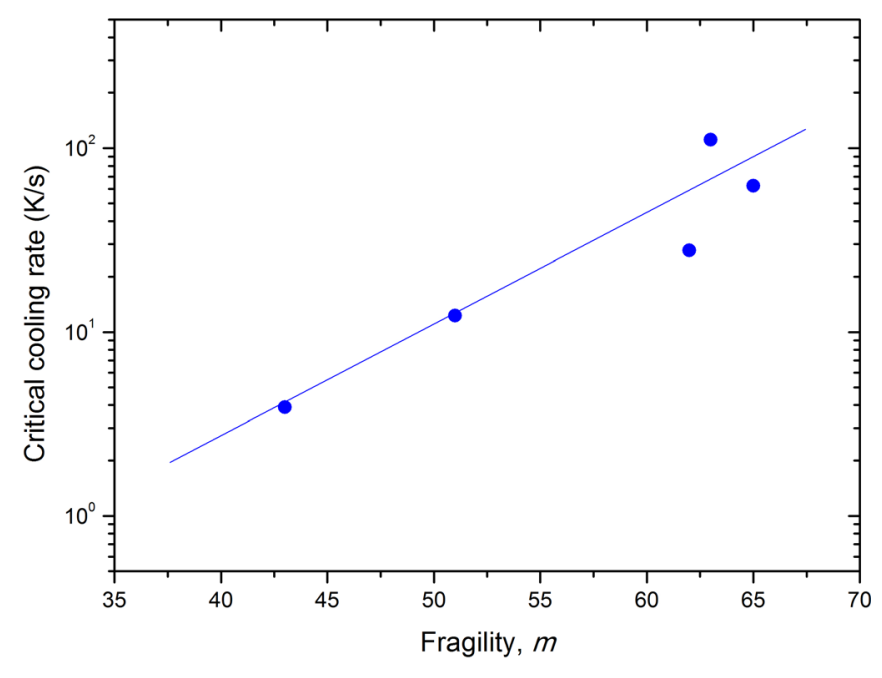

FIG. 4. (Color online) Correlation between fragility and critical cooling rate for various Fe-based bulk-glass-formers. Line is a regression through the data.

This work was supported by the National Research Foundation of Korea Grant funded by the Korean Government [NRF-2009-352-D00125] and by the MRSEC Program of the National Science Foundation [DMR-0520565].

${ }^{1}$ C. A. Angell, Science 267, 1924 (1995).

${ }^{2}$ V. N. Novikov and A. P. Sokolov, Nature 431, 961 (2004); S. N. Yiannopoulos, and G. P. Johari, Nature 442, E7 (2006).

${ }^{3}$ R. Busch, E. Bakke, and W. L. Johnson, Acta Mater. 46, 4725 (1998).

${ }^{4}$ Z. Evenson, S. Raedersdorf, I. Gallino, and R. Busch, Scr. Mater. 63, 573 (2010).

${ }^{5}$ G. J. Fan, H.-J. Fecht, and E. J. Lavernia, Appl. Phys. Lett. 84, 487 (2004). ${ }^{6}$ C. Zhang, L. Hu, Y. Yue, and J. C. Mauro, J. Chem. Phys. 133, 014508 (2010).

${ }^{7}$ Z. P. Lu, C. T. Liu, J. R. Thompson, and W. D. Porter, Phys. Rev. Lett. 92, 245503 (2004).

${ }^{8}$ V. Ponnambalam, S. J. Poon, and G. J. Shiflet, J. Mater. Res. 19, 1320 (2004).

${ }^{9}$ X. J. Gu, S. J. Poon, and G. J. Shiflet, J. Mater. Res. 22, 344 (2007).

${ }^{10}$ J. Shen, Q. Chen, J. Sun, H. Fan, and G. Wang, Appl. Phys. Lett. 86, 151907 (2005).

${ }^{11}$ M. D. Demetriou, G. Kaltenboeck, J. Y. Suh, G. Garrett, M. Floyd, C. Crewdson, D. C. Hofmann, H. Kozachkov, A. Wiest, J. P. Schramm, and W. L. Johnson, Appl. Phys. Lett. 95, 041907 (2009).

${ }^{12}$ X. J. Gu, S. J. Poon, G. J. Shiflet, and M. Widom, Acta Mater. 56, 88 (2008).

${ }^{13}$ K. Biswas, S. Venkataraman, W. Y. Zhang, S. Ram, and J. Eckert, J. Appl. Phys. 100, 023501 (2006).

${ }^{14}$ H. E. Hagy, J. Am. Ceram. Soc. 46, 93 (1963).

${ }^{15}$ W. L. Johnson and K. Samwer, Phys. Rev. Lett. 95, 195501 (2005).

${ }^{16}$ M. D. Demetriou, J. S. Harmon, M. Tao, G. Duan, K. Samwer, and W. L. Johnson, Phys. Rev. Lett. 97, 065502 (2006).

${ }^{17}$ W. L. Johnson, M. D. Demetriou, J. S. Harmon, M. L. Lind, and K. Samwer, MRS Bull. 32, 644 (2007).

${ }^{18}$ J. S. Harmon, M. D. Demetriou, and W. L. Johnson, Appl. Phys. Lett. 90, 171923 (2007). 